\title{
A Referência a Marx no Ensino de Lacan
}

\author{
Mauricio José d'Escragnolle Cardoso ${ }^{1}$ \\ Universidade Federal do Paraná \\ Vinicius Anciães Darriba \\ Universidade do Estado do Rio de Janeiro
}

\begin{abstract}
RESUMO - A referência a Marx forma uma constante no ensino de Lacan. Rastreando o conjunto de tais referências, vemos Marx surgir, desaparecer, para, logo em seguida, ressurgir no interior do pensamento lacaniano. Tal diálogo manifesta a persistência de um núcleo central. Nesse sentido, consideramos que o interesse de Lacan em formalizar a relação existente entre os conceitos de sujeito do significante, de Outro e de gozo constitui o núcleo de tal diálogo do começo ao fim. Nosso artigo tratará da recorrência desse núcleo temático, percorrendo sucessivamente três diferentes momentos desse diálogo na obra de Lacan.
\end{abstract}

Palavras-chave: Lacan, Marx, sujeito, outro, mais-valia, mais-de-gozar

\section{The Reference to Marx in Lacan's Teachings}

\begin{abstract}
The reference to Marx forms a constant in Lacan's teachings. Tracing all these references we see Marx emerge, disappear, then reappear in Lacanian thought. Such dialogue expresses the persistence of a central core. In this sense, we consider that the interest of Lacan to formalize the relationship between the concepts of subject of the signifier, Other and enjoyment is the core of this dialogue from beginning to end. Our paper will address the recurrence of this thematic cluster, successively traversing three different moments of dialogue in Lacan's work.
\end{abstract}

Keywords: Lacan, Marx, subject, other, surplus-value, surplus-enjoyment

A referência a Marx forma uma constante no ensino de Lacan. Rastreando o conjunto de tais referências, vemos Marx surgir, desaparecer, para, logo em seguida, vê-lo ressurgir no interior do pensamento lacaniano. Marx é um interlocutor privilegiado de Lacan, com o qual entretém um diálogo ao mesmo tempo contínuo e entrecortado. Lacan percebe que a psicanálise e a crítica marxiana da economia política são doutrinas muito próximas, tanto do ponto de vista doutrinário quanto metodológico. E, talvez por isso mesmo, vemo-lo continuamente preocupado em demarcar-se da filosofia de Marx no interior do mesmo movimento em que busca compreender tal proximidade, tanto do ponto de vista teórico quanto prático (1957-1958/1999, 1959-1960/2008, 1964/1988, 1966-1967/2008, 1968-1969/2008, 1975).

Entendemos que esse conjunto de referências de Lacan a Marx manifesta a persistência de um núcleo central que permanece o mesmo, para além da diversidade de conceitos e problemas envolvidos. Nesse sentido, consideramos que o interesse de Lacan em formalizar a relação existente entre os conceitos de sujeito do significante, de Outro e de gozo constitui o núcleo de tal diálogo do começo ao fim. Em outras palavras, Lacan percebe a profunda analogia entre a lógica da articulação dos conceitos de sujeito, Outro e gozo e aquela manifestada pelo enigma metafísico da forma-mercadoria no interior do mercado. Nosso artigo tratará da recorrência deste núcleo temático fundamental, percorrendo sucessivamente três diferentes momentos deste diálogo na obra de Lacan (1957-1958/1999, 1959-1960/2008, 1966-1967/2008, 19681969/2008, 1975).

1 Endereço para correspondência: Rua Leonor Castellano, 642, Pilarzinho, Curitiba, Paraná, PR, Brasil. CEP: 82.120-330. E-mail: descragnolle@yahoo.fr
Assim sendo, podemos perceber, no primeiro ensino de Lacan (1957-1958/1999, 1959-1960/2008), no final do período marcado pela tópica do imaginário e pelo início daquele estruturalista, a filosofia de Marx sendo utilizada com o intuito de contribuir para a inteligibilidade do processo de circulação de valores metonímicos envolvido na relação do sujeito ao desejo. Durante o segundo ensino de Lacan (1964/1988, 1966-1967/2008), pautado pela busca das consequências metapsicológicas do estruturalismo, Marx ressurge fornecendo elementos para sua reflexão acerca do estatuto do Outro. Finalmente, em um terceiro momento (1968-1969/2008, 1975), o interesse de Lacan por Marx dirige-se para o problema da mais-valia, em conformidade com as exigências teóricas do problema do gozo e do objeto. Se cada um dos conceitos ocupa posição central nos distintos tempos do diálogo de Lacan com Marx, suas respectivas problemáticas atravessam-se conjuntamente.

\section{Lacan: A Troca Significante e a Circulação do Objeto}

Podemos tomar como ponto de partida o Seminário As formações do inconsciente (Lacan, 1957-1958/1999), onde o diálogo de Lacan com Marx se inicia com a discussão da teoria do valor da mercadoria e, particularmente, do problema da circulação de equivalentes. Essa primeira referência de Lacan à obra marxiana pode ser encontrada no curso do dia 27 de novembro de 1957, uma aula dedicada à análise das relações existentes entre o chiste e a função metonímica(p. 69-86). Como entender os motivos de Lacan associar, no interior de uma sessão de seu seminário, no conjunto de uma 
mesma aula, a teoria da circulação de mercadorias, segundo Marx, a análise do Chiste, em Freud, e o que ele intitula "objeto metonìmico"?

Nessa lição (1957-1958/1999, p. 69-86), Lacan está tentando demonstrar para a sua audiência o quanto o inconsciente manifesta uma espécie de autonomia material, uma forma de determinação linguageira do sujeito, independente tanto da lógica abstrata do conceito (associada tradicionalmente a este aspecto de nossa consciência racional que a filosofia intitula entendimento) quanto da redução do inconsciente a uma função psicológica (característica do psicologismo que ele já havia assinalado com respeito à Psicologia do Eu). Por um lado, a sintaxe do inconsciente não condiz ao conceito, na medida em que este sempre pressupõe uma matéria exterior à sua natureza abstrata $\mathrm{e}$, por outro, sua estrutura metapsicológica não deve ser postulada de maneira psicologista, a qual reduziria os paradoxos do desejo a processos instintuais.

Contrária tanto ao estatuto claro e preciso dos conteúdos conceituais quanto ao naturalismo dos instintos, a forma própria do inconsciente concerne ao que Lacan (19571958/1999, p.71) designa como as "leis do significante", e somente a partir delas se poderia definir seu sujeito. Não é difícil percebermos o viés cartesiano do horizonte de problemas que Lacan visa abordar. Se, por um lado, tradicionalmente, identificamo-nos a esse domínio formado pela abstração ideal dos conteúdos da razão; por outro lado, depararamo-nos com a concretude de nossa existência biológica e corporal.

No entanto, a psicanálise busca seu sujeito no inconsciente, em uma instância irredutível às duas citadas. Como Freud (1915/1968, p. 17) já assinalara, seu estatuto ontológico é efetivamente muito mais próximo daquele de um "conceitolimite" do que de algo limitado pelo conceito, mais próximo de um intervalo "entre" substâncias do que de uma substância ela mesma. O inconsciente é algo muito mais da ordem de uma fratura ou um corte, do que do substrato onde esse corte ou essa fratura poderia ocorrer. Sentimo-nos tentados a situar o inconsciente, nesse sentido, através da mesma figura utilizada por Freud em sua tentativa de definir as pulsões e igualmente considerá-lo como uma instanciação de "um conceito-limite entre o psíquico e o somático" (p.17). Precisamente através de sua reflexão sobre o fenômeno do chiste, Lacan (1957-1958/1999, p. 97). tentará demonstrar, segundo uma estratégia epistemológica eminententemente clínica, que a atividade inconsciente (e suas formações) não deve ser confundida nem com o pensamento no sentido do entendimento - atividade coerente, auto-referente, transparente a si mesma, tradicionalmente associada à consciência racional; em termos kantianos, a capacidade de performar a síntese da unidade e da identidade do objeto a partir do diverso empírico na sensibilidade, etc - nem de sua simples negação sob forma orgânica, sobretudo tal como objetivada nas diversas ciências que abordam nossa corporalidade.

Como assinala Mladen Dolar (1998, p. 21; 40), o cogito cartesiano e seu dualismo de substâncias pode ser posto em paralelo com a famosa proposição freudiana wo es war, soll ich werden ("onde isso era, eu devo advir"), com qual a psicanálise fornece uma fórmula para a subversão não apenas do sujeito cartesiano da ciência como também de seu correlato orgânico, oferecendo a substituição da cópula pela alienação inconsciente e sua função particularmente disjuntiva do Ser e do Pensar. $\mathrm{O}$ wo es war freudiano, o cogito metapsicológico, seria o derradeiro chiste moderno, indicando que não somos mais uma presença instintiva (onde isso era, conjugado no passado) mas tampouco chegamos a ser um puro entendimento racional (eu devo advir, conjugado no futuro) (Freud, 1933/1984, p. 110). Como se após a enunciação por Descartes do cogito, Freud (1933/1984) devolvesse como réplica o chiste de sua proposição ("onde isso era, eu devo advir"). Trata-se aí de uma réplica chistosa do próprio cogito, retrucando contra a afirmação do "Eu penso, logo eu sou" um "Eu não sou mais..., e, bom, nem tampouco me tornei ainda...!".

O sujeito da psicanálise se encontra nesse espaço difícil de ser circunscrito, um espaço-limite no qual já abandonamos nosso determinismo biológico, sem, no entanto, tornarmonos ainda um puro entendimento racional. Eis aí o motivo de Lacan (1957-1958/1999) introduzir sua reflexão acerca da lógica do significante através da análise do chiste, um exemplo perfeitamente freudiano dessa possibilidade terceira entre entendimento e corporalidade. Nele, os processos significantes seriam, ao mesmo tempo, refratários ao conceito - pois baseados no equívoco e na ambiguidade, ao invés da coerência e transparência cognitivas - e contrários à primazia do naturalismo psicológico, posto referirem-se, sobretudo, a uma experiência estética eminentemente inútil do ponto de vista de todo determinismo instintual. Para Lacan, a especificidade do processo do chiste deverá ser procurada unicamente na atividade simbólica envolvida em sua produção e em sua comunicação, em seus aspectos unicamente simbólicos e sociais. $\mathrm{O}$ único valor do chiste e, nesse sentido, intrínsecamente associado a uma relação intersubjetiva - reside no "nível da circulação do significante" (p. 97). O chiste assinala a existência de uma estrutura significante que torna possível o deslocamento de certa quantidade indeterminada de gozo no campo de uma forma de subjetividade não mais possuidora de nenhum dos atributos tradicionamente conferidos à consciência, mas tampouco por isso mais dependente da organicidade. $\mathrm{O}$ chiste assinala nossa passagem para uma dimensão do psiquismo diretamente oriunda de nossa entrada na ordem simbólica, mas, ao mesmo tempo, determinada unicamente por uma circulação de gozo sustentada pelos equívocos e ambiguidades que o discurso concreto é capaz de manifestar e, por isso, irredutível tanto às formas conscienciais do entendimento quanto aos processos fisiológicos naturais.

Para exemplificar esta lógica que seu argumento se esforça em circunscrever, Lacan (1957-1958/1999, p. 73) cita um chiste de Henrich Heine replicando a Frédéric Soulié, acerca do Veau d'Or/Bezerro de Ouro, citado por Freud em sua obra sobre o tema (1905/1988, p.108), como um exemplo de chiste por deslocamento (Blanco, 2002, p. 81):

Conta-se a estória de que, em certo fim de tarde, Heine conversava em um salon de Paris com o dramaturgo Soulié, quando adentrou à sala um dos reis das finanças de Paris, comparado popularmente a Midas - e não apenas por sua riqueza. Logo foi cercado por uma multidão que o tratava com a maior deferência. "Veja!" observou Soulié a Heine, "veja como o século 
XIX cultua o Bezerro de Ouro! [veau d'or]. ” Com uma rápida mirada ao objeto de tanta admiração, Heine replicou, como que a bem da correção: "Oh, sim, mas ele parece já um pouco passado!” (Freud, 1905/1988, p.108).

Para Lacan (1957-1958/1999), o segredo do mecanismo do chiste não deve ser buscado nem em algum processo psicológico nem exclusivamente naquilo do que fala o chiste como referente semântico, mas, sobretudo, no fato mesmo do jogo significante envolvido nas ambiguidades e equívocos possibilitados pela sua própria forma simbólica. O enigma do chiste reside em saber de que maneira a articulação entre significantes torna possível uma espécie de satisfação subjetiva, uma forma de gozo. Se o segredo do chiste repousa somente em sua própria forma; se na análise do chiste atemonos ao seu próprio simbolismo, tornar-se-á perceptível o quanto o efeito do chiste deve à própria "materialidade do significante" (p.73). É por esse motivo que a questão incide sobre como é possível uma satisfação unicamente devida à forma material do significante e à sua operação no interior de uma troca ou circulação discursiva intersubjetiva. O chiste tornaria, assim, manifesto um tipo de gozo isento de toda forma de naturalização, um gozo propriamente metapsicológico.

Para Lacan (1957-1958/1999), haveria então uma fundamental homologia entre a lógica do significante, tal como exemplificada pelo chiste, e aquela referente à mercadoria em Marx: em ambas encontraríamos a imanência de um fenômeno ligado exclusivamente à potência de uma estrutura formal. Análogo à forma da circulação de mercadorias em um sistema de trocas e, sobretudo, ao que concerne à posição de equivalências de valor, o chiste manifesta através de uma função metonímica, na concatenação significante no interior da sintagmação, "uma transferência de significação ao longo da cadeia" (p.78), significação que é justamente o gozo para um sujeito do inconsciente.

O chiste do Veau d'Or é particularmente significativo a esse respeito. Nele veríamos o duplo movimento envolvido na circulação significante: junto à circulação da enunciação e, consequentemente, dos enunciados entre os sujeitos envolvidos no chiste - o diálogo desdobrado entre F. Soulié e H. Heine -, ocorreria também um deslocamento de sentido no interior do sintagma unicamente por contiguidade (Blanco, 2002, p. 81). Enquanto F. Soulié enfatiza o termo Ouro, H. Heine replica enfatizando o termo Bezerro. Nesse contexto, Lacan (1957-1958/1999) introduz uma referência explícita a Marx, dizendo que:

no simples desenrolar da cadeia significante, produz-se uma equalização, um nivelamento, de equivalência. É um apagamento ou uma redução do sentido, mas isso não quer dizer que seja do sem-sentido (non-sense). Eu havia adotado com respeito a isso a referência marxista - pôr em função dois objetos da ordem da necessidade de tal maneira que um se torna a medida do valor do outro, apaga do objeto isso que é precisamente a ordem da necessidade e o introduz assim na ordem do valor.

Uma vez que vós tereis esta chave, a significação da cadeia metonimica não faltará a vos aparecer. (p.86)

Devemos lembrar que a referência de Lacan (19571958/1999) encontra-se na poética Jakobsoniana, na qual a metonímia apresenta uma figura de discurso em que a substituição lexical assenta-se na contiguidade associativa e cujos exemplos mais transparentes são marcados pela prosódia e pela aliteração. É por esse motivo que o aspecto da metonímia que mais interessa a Lacan concerne ao que Jakobson (1963) intitula contextura:

Todo signo é composto de signos constituintes elou aparece em combinação com outros signos. Isso significa que toda unidade linguística serve ao mesmo tempo de contexto a outras unidades mais simples elou encontra seu próprio contexto em uma unidade linguística mais complexa (p. 48).

Se a contextura permite que a materialidade do significante influa na função de reenvio a outros significantes, como no caso da poesia, inversamente também permite que se escutem novas cadeias (lexicais ou sintagmáticas) em um mesmo fragmento sonoro. Nessa composição e recomposição, circularia alguma coisa que, mesmo servindo para a comunicação de conteúdos, demarca, na verdade, uma destituição de seus privilégios, muito mais condizente com certo gozo estético, inútil do ponto de vista da informação utilitária. O que é veiculado pelo chiste, mais do que uma informação, é o gozo de sua própria enunciação.

Lacan (1957-1958/1999) intitula essa quantidade de valor de gozo que se desloca pelos diferentes significantes quando da formação do chiste de objeto metonímico, objeto que “é sempre outra coisa" (p. 22). Ele constitui o "objeto que não pode ser nomeado" (p. 64) na medida em que fornece o limite do dizível, indicando, assim, o resíduo irredutível ligado ao significante presente no coração dos processos chistosos formados por contextura. $\mathrm{O}$ que caracteriza esse objeto é o fato de ele ser inapreensível de maneira direta, escorregadio (glissant), constituinte ele mesmo de um limite da representação e, logo, limite do significado. Significação limitante do significado, valor que não se reduz ao sentido, o objeto metonímico, objeto circulante, é "uma significação que sempre desliza, escoa e se furta", fazendo com que "a significação seja, em virtude da existência do significante, um objeto de um tipo especial" (p.240), aquele ao que corresponde um sujeito tal como o do inconsciente.

Ressaltemos o quanto esse objeto é realmente especial, na medida em que retira a significação do campo propriamente dito do significado, localizando-a em uma pura intensidade libidinal. É esse valor libidinal o que se desloca e assenta o chiste em seu estatuto poético e que, enquanto tal, pressupõe necessariamente uma categoria de sujeito que não o refira ao entendimento de conceitos, mas a uma satisfação de ordem muito mais estética.

Nesse sentido original da metonímia, ou seja, no sentido freudiano de deslocamento, encontramos a tradução lacaniana do problema da circulação de valores. É por isso que Lacan pôs em relevo a questão do fragmento ou da fragmentação (Blanco, 2002, p. 87): quando de sua análise da contextura metonímica, a transferência de investimento libidinal, o deslocamento dos valores referidos aos significantes, depende de que um significante represente junto a outro a possibilidade de encarnar uma quantidade específica de satisfação para um sujeito. E, nesse caso, o objeto metonímico basta para sustentar a contiguidade contextural entre esses significantes. 


\section{Do Fetichismo ao Processo de Alienação em Marx e Lacan}

A característica mais espetacular da universalização e da autonomização da circulação de valores em situação capitalista é o que Marx (1867/1993) chamou de fenômeno do fetichismo da mercadoria:

A forma valor e a relação de valor dos produtos do trabalho não têm absolutamente nada a fazer com sua natureza fisica. É somente uma relação social determinada dos homens entre eles que reveste aqui para eles a forma fantástica de uma relação das coisas entre elas. Para encontrar uma analogia a este fenômeno, é preciso buscá-la na região nebulosa do mundo religioso. Ai os produtos do cérebro humano têm o aspecto de seres independentes, dotados de corpos particulares, em comunicação com os homens e entre eles. Acontece o mesmo com os produtos da mão do homem no mundo mercantil. É isso que podemos nomear como o fetichismo ligado aos produtos do trabalho, desde que eles apresentam-se como mercadorias, fetichismo inseparável deste modo de produção. (p. 83)

A estrutura do fetiche é a mesma que em Freud, pois se trata aqui, como diz Lacan (1966-1967/2008), de introduzir "isso que Marx e nós mesmos chamamos o fetiche, a saber, este valor de uso, extraído, fixado - um furo em algum lugar o único ponto de inserção necessário a toda ideologia sexual" (p. 304). O fetiche é a transformação de um significante em signo do valor, consequentemente não mais um significante propriamente dito, mas um signo-objeto capaz de realizar a hipóstase entre valor de troca e valor de uso, tal como definido por Marx.

A estrita homologia entre a definição da mercadoria como objeto sensivel suprassensivel (isto é, objetos que recaem e não recaem sob os sentidos) e a concepção lacaniana do signo-fetiche como um objeto nem real, nem irreal, como uma fenomenalidade que transcende a tradicional oposição entre o real e o aparente, aplica-se, sobretudo, à moeda e seu estatuto de equivalente-geral. Da mesma maneira que, no caso da moeda, cujo valor de uso é ser um valor de troca, o fetiche não é propriamente dito um objeto, mas a transformação de um objeto em um signo do valor. É nesse sentido que o fetiche é precisamente esse fenômeno no qual a estrutura formal do valor aparece para si mesma como sendo a propriedade positiva de um elemento particular, e como se essa positividade fosse independente da rede de relações que forma o sistema do qual ele faz parte.

Como indica Zizek (1992, p.76), essa característica reflexiva da forma-valor equivalente trata a inconsistência de uma maneira bastante particular. O equivalente-geral completa o sistema de uma maneira específica, na medida em que ele não é simplesmente o complemento que faltaria ao sistema, tornando-o consistente. O fetiche assume, segundo o filósofo esloveno, o lugar da própria inconsistência (Zizek, 1991, p.151). Assim, o signo-fetiche, equivalente-geral, não é alguma coisa que viria apenas a obturar o vazio que funciona como fundamento de um sistema de valores, mas uma forma de inscrição da própria ausência.

Sob o rosto do equivalente, um vazio empírico consegue encarnar-se. É neste sentido que a função fetiche indica a própria ausência de exterioridade que caracteriza um sistema de valores. O equivalente, como diz Marx (1867/1993, p.76), encena o papel de um espelho que refletiria unicamente a própria existência dos valores e, por isso mesmo, não reflete mais nada. Mas, precisamente, enquanto espelho de todo o sistema de valores, o equivalente-geral mostra, reflete, o próprio invisível: ele não é nada mais que a positivação de uma negatividade.

Como assinala Zizek (1991, p.141), no equivalente-geral, protótipo do fetichismo da mercadoria, a universalidade formal do valor manifesta-se e somente pode expressar-se sob o modo de seu contrário, ou seja, na figura de uma substância particular. O mistério reside então na lógica que sustenta a expressão da dimensão imaterial das relações simbólicas sob a forma de uma propriedade material inerente a um objeto específico. Como diz Marx (1867/1993), em uma passagem já famosa: "É assim que o particular A não saberia representar para o indivíduo B uma majestade, sem que a majestade aos olhos de $\mathrm{B}$ não revista imediatamente tanto a imagem quanto o corpo de A" (p. 59).

É interessante notarmos que Marx (1867/1993, p. 59) propõe abordar esse sistema de equivalências relativas entre diferentes expressões de formas-valor como análogo a um sistema simbólico, ou seja, como possuindo uma estrutura formal. Quais são as características maiores dessa analogia? Em primeiro lugar, uma mercadoria não pode representar seu próprio valor, sendo então necessária sua participação em um sistema de relações diferenciais. Em segundo lugar, em um sistema de relações, o valor de uso de uma mercadoria torna-se a forma de expressão de seu contrário, isto é, do valor de troca de outra mercadoria, surgindo, dessa maneira, a característica maior do fetichismo da forma-valor equivalente.

Chega-se à estrutura da forma-valor generalizada quando todos os componentes naturais, privados e concretos são subsumidos pelo sistema universal de produção e circulação de formas-valor. Nesse momento, esse sistema autonomizase de toda finalidade humana e universaliza-se a todos os componentes da ordem social, incluindo, sobretudo, o último bastião que resistia à subsunção geral, isto é, o trabalho humano ele mesmo. A forma-valor generalizada é, assim, "a primeira que coloca as mercadorias em relação entre elas como valores, fazendo aparecer uma diante da outra como valores de troca" (Marx, 1867/1993, p. 75). Ou seja, quando chegamos à universalização e à autonomização do circuito da forma-valor, nada mais existe de maneira exterior ao universo da circulação, não existe mais exterioridade à dimensão do valor. E, nesse momento, o circuito da troca se torna circular.

Um dos efeitos dessa dinâmica estrutural autônoma e circular é a alienação. O conceito de alienação significa que o homem se torna um ser dividido, pois sua identidade a si somente se realiza sob a forma de seu contrário. O homem realiza-se no interior desse processo, ao mesmo tempo atividade produtiva e trabalho coagulado sob a efígie da mercadoria. Manifestando-se como sujeito e como objeto, o homem adquire uma identidade social na medida em que se exterioriza sob a forma de seu contrário. E, finalmente, na alienação, a representação do sujeito por um elemento simbólico produz um termo que é simultaneamente vazio da representação e subproduto excedente. Toda vez que há alienação, ocorre necessariamente divisão constitutiva, identidade de contrários e produção de um excedente 
que encarna a essência significante do sujeito de maneira objetivada.

Bensussan e Labica (1982) assinalam que, somente com Hegel, a noção adquire um estatuto propriamente filosófico, abandonando a dimensão jurídico-econômica em nome daquela propriamente relacionada à economia política. A partir de então, o termo alienação passa a se referir a Entfremdung, um "tornado-estrangeiro" (p. 17) e, mais precisamente, um tornar-se estranho, desconhecido, ou seja, um separar-se de si mesmo e realizar-se sob a forma de uma cisão, de uma Spaltung que se nega a si mesma de maneira invertida e hipostasiada. Ou seja, neste caso, não se trata mais de ceder algo da ordem de uma propriedade, mas, ao contrário, de um perder-se em outro, isto é, de uma forma de divórcio de si mesmo referido ao campo do Ser (Bensussan \& Labica, 1982, p.18-19).

Ainda segundo Bensussan e Labica (1982, p.17), é esse sentido do termo alienação que formará a base da noção marxiana de alienação. Na alienação religiosa, não se trata de um homem despossuído de um bem, mas de um modo do homem realizar sua relação consigo mesmo sob a forma de sua divisão exteriorizada de maneira invertida. Nesse caso, o homem não aliena uma propriedade privada: ao contrário, de um modo muito mais radical, ele aliena a si mesmo, exterioriza a sua essência em uma espécie de inversão que apaga os vestígios de seu próprio movimento em uma hipóstase semelhante àquela encontrada nos processos de reificação e de fetichização. É na transposição desse segundo sentido do conceito do campo da crítica da religião para aquele da crítica da economia política que encontraríamos a origem da noção de alienação em Marx (Bensussan \& Labica, 1982, p. 17). E é nessa linhagem que vai de Hegel a Marx que se inscreve a leitura lacaniana do processo de alienação, tal como o próprio autor assinala:

Quando Hegel nos introduz ao princípio da alienação, é exatamente aí que eu encontrei legitimamente a justificação de chamá-lo o vel "alienante". De que se trata? Economizemos nossos traços. Trata-se de engendrar a primeira alienação, aquela através da qual o homem entre na via da escravidão. A liberdade ou a vida. Se ele escolhe a liberdade, Opa! ele perde as duas imediatamente. Se ele escolhe a vida, ele possui a vida amputada da liberdade. (Lacan, 1964/1988, p. 201)

Dessa maneira, Lacan (1966-1967/2008) estava bem advertido da origem e do sentido do termo alienação no pensamento marxiano, como demonstra ao afirmar que:

Marx nos diz, em algum lugar dos Manifestos filosóficos, que o objeto do homem não é nada mais que sua essência-mesma tomada como objeto; que o objeto também, ao qual um sujeito se endereça, por essência e necessariamente, não é nada mais que a essência própria deste sujeito não objetivada. [...] Este objeto do qual se trata, esta essência próprio do sujeito, mas objetivada, não seríamos nós que podemos dela fornecer sua verdadeira substância? (p.300)

Em outras palavras, a psicanálise seria apta a fornecer uma explicação dessa passagem da essência ao objeto, seria capaz de explicar de que maneira aquilo que concerne à essência do sujeito - isto é, algo da ordem simbólica e, consequentemente, pertencente ao registro do significante manifestar-se-ia sob a forma da objetivação, ou seja, tornada existência separada para um sujeito como objeto.
Lembremos, para entender essa passagem do Seminário (1966-1967/2008), que o termo das Fremde, presente em Entfremdung, é correntemente traduzido como o Outro (Bensussan \& Labica, 1982, p. 18), na medida em que a alteridade do outro é aquilo que caracteriza seu ser estranho, estrangeiro, desconhecido, separado de mim de maneira hipostasiada. Nesse caso, a lição, segundo Bensussan e Labica (1982, p.18), consiste em perceber que, por um lado, se a alienação é um realizar-se como outro que, sob a forma da consciência invertida, implica necessariamente um desconhecer-se; por outro, o mecanismo da alienação implica fazer desse distanciar-se de si uma maneira (eminentemente moderna, diga-se de passagem) de relacionar-se consigo mesmo.

Partindo dessa constatação, é interessante notarmos que o primeiro tratamento oferecido por Lacan (1959-1960/2008) ao problema do fremde Objekt e, consequentemente, do correlato objetal da alienação enquanto Entfremdung aparece na quarta lição de dezembro de 1959, em seu Seminário sobre a Ética da Psicanálise, referido à experiência do Nebenmensch (p. 67). Freud (1895) se refere a essa experiência em seu Projeto de Psicologia para Neurólogos, no qual a qualidade de estranho, de fremde, é aquilo que caracteriza das Ding, o objeto por excelência estrangeiro a toda possibilidade de representação (Lacan, 1959-1960/2008, p.67), e que, ao mesmo tempo, indica nossa entrada no campo do significante. Segundo Lacan:

a noção deste Ding, deste Ding como fremde, como estrangeiro, e mesmo no caso hostil, em todo caso como o primeiro exterior, eis ai este em torno do quê orienta-se todo o progresso que, sem dúvida, para o sujeito, é a todo instante percurso de controle, percurso de referência, com respeito ao quê? O mundo de seus desejos. (p. 67)

O objeto das Ding é definido por Lacan (1959-1960/2008, p. 88) como o "Outro absoluto" do sujeito, ou seja, não somente o outro do sujeito, seu correlato alteritário, mas, igualmente, um outro absoluto, ou seja, postulado como uma existência externa e independente de toda atividade subjetiva, como uma referência mais real que a própria realidade. É nesse sentido de um absoluto, ou seja, de um referente externo existente em si mesmo, que se pode afirmar que o fremde Objekt, estranho e estrangeiro:

está justamente no centro do sentido do qual ele é excluído, isto é, que na verdade ele será posto como exterior, este das Ding, [....], sob a forma de alguma coisa que é Entfremdet, estrangeira ao eu, ao mesmo tempo em que está no coração deste eu, esta alguma coisa que no nível do inconsciente unicamente representa uma representação. (p. 89)

Nosso problema concerne à exigência de entendermos de que maneira a alienação enquanto Entfremdung, isto é, a exteriorização política da essência do sujeito de maneira objetivada, relaciona-se com a percepção pelo sujeito do caráter absoluto desse outro, ou seja, de sua posição de maneira invertida, situando-se externamente ao Eu como existência separada e independente. Para isso, é necessário introduzirmos, além da referência de Lacan (19591960/2008) durante seu sétimo Seminário, o mecanismo que Lacan intitula propriamente de Alienação em Os quatro conceitos fundamentais da psicanálise (1964/1988). 
Neste seminário, Lacan (1964/1988) retoma os elementos que ele mesmo já havia desenvolvido em seu seminário sobre a Ética da Psicanálise (1959-1960/2008) no intuito de introduzir o processo da alienação. Lacan então comenta:

Isso que não favorece a homeostase, isso que se mantém, a todo preço, como Unlust, morde ainda muito mais em seu campo. E, é assim que isso que é da ordem do Unlust, ai inscreve-se como não-eu, como negação do eu, como redução do eu. O não-eu não se confunde com isso que o cerca, a vastidão do real, o não-eu se distingue como corpo estrangeiro, fremde Objekt. Ele está aí, situado na intersecção que estes dois pequenos círculos a la Euler constituem. (Lacan, 1964/1988, p. 232)

É na intersecção entre o círculo do sujeito e a esfera do Outro que se situa o objeto-estrangeiro, fremde Objekt. E é nesse sentido que dissemos estar Lacan bem advertido do esquema teórico marxiano, pois afirma que encontramos aí a forma mesma da estrutura da relação do sujeito ao Outro. O sujeito lacaniano, tal como o proletário em Marx, constitui-se a partir de uma divisão que responde ao modelo lógico-dialético da alienação. O sujeito somente possui uma identidade, uma representação pelo significante, a partir de sua divisão, na medida em que sacrifica seu vazio sob a forma de seu contrário, ou seja, como objeto.

O sujeito metapsicológico nasce justamente quando a ordem da necessidade e da satisfação privada e concreta é substituída por uma ordem de valores abstrata e social que somente o contempla a partir de uma renúncia autoinflingida, da mesma maneira que toda alienação é sempre auto-alienação. Se o sistema de equivalências e circulação de valores é o Outro; o inconsciente, do ponto de vista pulsional, surge quando a finalidade da circulação deixa de ser guiada por toda finalidade humana, seja ela a homeostase, o equilíbrio, a preservação do indivíduo ou seu bem-estar, quando ela não visa mais que seus próprios interesses, de maneira circular e autônoma.

Sabemos que a forma essencial da alienação em Marx se dá sob a forma do trabalho alienado. Mas, não seria esta a definição mesma do inconsciente? O inconsciente é por excelência um tipo de atividade simbólica da qual o Eu não pode dispor a seu proveito, nem tampouco na qual pode reconhecer-se. Além disso, sob a forma do Outro, o inconsciente é aquilo que remete à produção de um excedente que necessariamente se apresenta como um não-eu que se realiza de maneira invertida e objetivada, transposta para a realidade da prática social do sujeito sob a forma eminente do desprazer. Daí Lacan (1964/1988) afirmar: "tudo isso que, na repetição, se varia, se modula, não é nada mais que a alienação de sua essência" (p. 62), que se faz sob a forma da alienação de certos restos, de elementos expulsados.

O processo de alienação implica, desse modo, uma divisão no sujeito diante de uma escolha que se oferece como forçada entre aquilo que é da ordem do sentido oferecido pela representação pelo significante (pelo Outro) e a ameaça de sua aphanisis. É nesse contexto de ameaça de desaparição que a questão da escolha forçada entre o sentido e o ser não concerne a uma falsa escolha (na qual, sendo forçada, somente haveria uma), mas, ao contrário, constitui o modelo mesmo de toda escolha genuína. Em outras palavras, é justamente na medida em que a escolha é genuína, ou seja, um puro ato de precipitação, que ela implica a dupla negação tanto do ser - pois algo que é não necessita nada escolher quanto a isso - quanto do sentido - pois uma escolha, na acepção forte do termo, nunca é integralmente justificada.

Por um lado, o sujeito escolhe a auto-alienação de sua essência em nome de sua inscrição na ordem do sentido, o que implica considerar que ele pressupõe uma essência anterior à sua escolha (a essência deve aqui ser entendida como produção performativa desse fundamento anterior de si), mas, por outro lado, ele paradoxalmente somente ganha uma existência simbólica quando se encontra desprovido de essência própria, ou seja, representado pelo Outro do sentido. No entanto, uma vez obtendo uma existência simbólica pelo Outro (ou seja, desprovido de essência imanente), o sujeito somente pode apreender-se como mutilado, despossuído de algo que lhe aparece agora de maneira objetivada, como se algo lhe tivesse sido extraído, ao mesmo tempo em que se ressente de um sentido que lhe parece inautêntico.

\section{Sobre a Relação entre Mais-Valia e Mais-de- Gozar}

Na primeira lição de O Seminário 16, Lacan (19681969/2008) explicita seu projeto para aquele ano: "É de um nível homológico calcado em Marx que partirei para introduzir hoje o lugar em que temos de situar a função essencial do objeto a" (p. 16). A homologia da qual Lacan fala concerne à ideia de mais-valia de Marx, à qual ele articula sua ideia do mais-de-gozar: "Nessa mais-valia, portanto, prendi, superpus, pespeguei no avesso a ideia de mais-de-gozar" ( $\mathrm{p}$. 29). Trata-se para Lacan, com a introdução do mais-de-gozar, da exploração, portanto, do que seria a função essencial do objeto a. Indissociável do advento de uma teoria dos discursos no contexto de seu ensino, a mais-valia, tornada modelo do mais-de-gozar, torna possível compreender de que maneira o gozo pode ser produzido/extraído pelo que nos pareceria o mais distante da experiência corporal, por algo de ordem eminentemente estrutural.

Partamos da definição lacaniana da mais-valia de Marx:

Remuneramos o trabalho com dinheiro, uma vez que estamos no mercado. Pagamos seu preço verdadeiro, tal como a função do valor de troca o define no mercado. No entanto, existe um valor não remunerado naquilo que aparece como fruto do trabalho, porque o preço verdadeiro desse fruto está em seu valor de uso. Esse trabalho não remunerado, embora pago de maneira justa em relação à consistência do mercado no funcionamento do sujeito capitalista, é a mais-valia (Lacan, 1968-1969/2008, p.37).

Como assinala Zizek (1992), Lacan está bem advertido da presença de certo paradoxo no protótipo da relação de justa troca: apesar do capital adquirir, sob a forma da propriedade privada, a força de trabalho de outrem em seu justo valor, o consumo dessa força sob a forma da mercadoria produz algo não originalmente previsto, produz um excedente. A questão obviamente comporta dois aspetos. Como o consumo, que por definição implica necessariamente a destruição do objeto, pode gerar um excesso e não uma carência? Como uma extração que sabemos não ser formalmente excessiva, na qual não existe qualquer forma de exploração do ponto de 
vista da idealidade da troca do trabalho pelo capital, pode, simultaneamente, implicar a produção da mais-valia?

O que importa a Lacan (1968-1969/2008) na decifração marxiana de tal realidade econômica é que, ao ser o sujeito do valor de troca representado perante o valor de uso, nessa brecha "se produz e cai a chamada mais-valia" (p. 21). É aí, no que ele entende haver de inaugural em Marx, que incide a homologia através da qual a perda em jogo passa a ser tomada nos termos do mais-de-gozar.

O ensino de Lacan (1968-1969/2008) estabelece que "o sujeito, seja qual for a forma em que se produza em sua presença, não pode reunir-se em seu representante de significante sem que se produza, na identidade, uma perda, propriamente chamada de objeto a" (p. 21). No entanto, pela homologia com a mais-valia, fica estabelecido que a parte perdida, não situável no circuito da troca, corresponde a uma quantidade suplementar cuja característica particular é de estar conjugada a uma estranha forma de recuperação. É nesse sentido que Lacan (1969-1970/1992) diz: “O que é que isso paga, pergunta ele - senão justamente o gozo, o qual é preciso que vá para algum lugar" (p. 17).

$\mathrm{Na}$ troca econômica produtiva, encontramos uma dinâmica invertida com respeito à circulação de mercadorias no mercado, pois, se esta é a representante de uma recuperação extrínseca aos interesses do sistema de troca produtiva, aquela é o índice de uma extração do excesso. Quando entramos no regime da troca produtiva, passamos do ponto de vista do agente da troca - trabalhador assalariado ou consumidor simples, os quais buscam sempre uma finalidade extrínseca com respeito aos interesses do mercado - para a perspectiva, para o impossível ponto de vista do próprio circuito do capital, o qual visa simplesmente sua autorreprodução. Ou, segundo Marx (1867/1993):

A circulação simples - vender para comprar - somente serve como meio de atingir uma finalidade fora dela mesma, isto é, a apropriação de valores de uso, de coisas capazes de satisfazer necessidades determinadas. A circulação do dinheiro como capital possui ao contrário sua finalidade em si mesma, pois é somente por este movimento sempre renovado que o valor continua a fazer-se valer. O movimento do capital não possui então mais limites (p. 171).

A mais-valia implica que o valor "se apresenta subitamente como uma substância motora de si mesmo e para a qual tanto a mercadoria quanto o dinheiro somente são suas formas puras" (Marx, 1867/1993, p. 174). A mais-valia, nesse sentido, é a única substância inteiramente produzida como consequência do próprio sistema do valor. Ela é uma contradição encarnada, uma substância simbólica cujo único uso é o relançar da produtividade abstrata.

É nesse sentido que a mais-valia indica um limite interno ao sistema do capital, pois sua produção indica a subsunção completa da realidade pela ordem do valor, o fato de que a dimensão da troca não possui mais nada que lhe seja exterior (nem mesmo finalidades). No entanto, na medida em que é formada pela identidade de contrários, a mais-valia também encarna uma impossibilidade própria ao mesmo sistema.

A renovação ou a repetição da venda de mercadorias para a compra de outras mercadorias encontra, fora da circulação, um limite no consumo, na satisfação de necessidades determinadas. Na compra para a venda, ao contrário, o começo e o fim são uma única e mesma coisa, o dinheiro, o valor de troca e esta identidade destes dois termos faz com que o movimento seja infinito. (Marx, 1867/1993, p.171)

É assim que a mais-valia revela-se como a encarnação simbólica do próprio limite interno ao sistema produtivo, no que esse limite confunde-se com a própria ausência de exterioridade. É dessa maneira que o trabalho alienado pelo salário - justamente homólogo à alienação do sujeito ao significante-somente realiza valores que servem unicamente para retornarem ao sistema produtivo enquanto componentes para novas realizações de valor. A mais-valia não é nada mais que uma autolimitação simbólica que, na medida em que se situa internamente ao próprio sistema econômico, implica a infinitização de seu desdobramento. Como disse Lacan (1968-1969/2008):

em seu nível, a experiência analítica situa em algum lugar o ponto do infinito de tudo o que se ordena na ordem das combinações significantes. Esse ponto no infinito é irredutivel, porquanto concerne a um certo gozo que se mantém problemático, na medida em que instaura a questão do gozo sob um aspecto que já não é externo ao sistema do saber. (p. 320)

A mais-valia é o signo de que a atividade econômica do homem, enquanto atividade simbólica e não mecânica (natural), perdeu seu caráter propriamente humano, que ela deixou para trás sua finitude. Enquanto tal, ela não é uma atividade simplesmente reprodutora, mas inaugura uma nova forma de produtividade, criadora de diferenças e de novas formas de positividade, erigindo, por si só, um tipo inteiramente novo de infinitude. É nesse sentido que a homologia entre mais-valia e mais-de-gozar permite apreender essa forma de positividade estritamente correlacionada ao sistema das diferenças simbólicas, como uma espécie de elemento sígnico no interior do regime significante, como resultado excessivo inerente à dimensão da perda. Assim, se é possível afirmar a identidade estrutural entre mais-valia e mais-de-gozar, torna-se uma consequência evidente a mesma identidade entre a economia política e a economia libidinal.

O que encarna, no seio da ordem simbólica, esse valor ao mesmo tempo insensato (já que se caracteriza pela ausência de toda finalidade humana) e inteiramente racional (pois orientado exclusivamente pela abstração da idealidade do mercado) de mais-de-gozar é assim o que, em termos metapsicológicos, designa-se como objeto a. Isto é, o objeto ao mesmo tempo sensível e suprassensível, que ocupa um lugar de exceção interna, de extimidade, com respeito à absolutização do sistema simbólico de troca de valores.

Lembremos aqui que, na mercadoria-moeda (ou seja, no dinheiro) - exemplo maior do fetichismo da mercadoria - percebemos de maneira naturalizada esse recobrimento integral do campo dos valores de uso pelo do valor de troca. O dinheiro é a mercadoria inteiramente fetichizada, na medida em que sua função de uso é, por definição, ser unicamente o significante da troca. O dinheiro é, dessa maneira, o significante que pode trocar a si mesmo para si mesmo, ou seja, a função significante cujo significado é encarnar a reflexividade do sistema, ou seja, a subsunção integral da realidade pelo campo dos valores. O dinheiro assinala que o campo da idealidade paradoxalmente foi capaz de abandonar seu caráter de abstração - no sentido 
de sua oposição à realidade empírica - e, voltando-se para a terra, para a experiência humana concreta, torna-se um conceito sociologicamente efetivo, um conceito prático e não teorético (ou seja, em termos lacanianos, uma expressão do Grande Outro).

A mais-valia, por sua vez, deve ser entendida como seu contraponto necessariamente não-subjetivado. Nesse caso, não estamos mais no campo da mercadoria-moeda, mas naquele do capital. Através dessa inversão - da moeda ao capital, do campo do significante para aquele do objeto -, o registro simbólico é destotalizado. A referência à moeda ainda serve para a consistência ao Outro do mercado, por exemplo, como nos mostra o mito smithiano da mão invisível do mercado, ou na pressuposição de seu caráter racional. A moeda sempre inscreve uma referência à face reguladora da lei e nos abre à experiência de um ambiente juridicamente consolidado (o próprio mercado). Por outro lado, o estatuto causal do capital introduz um viés de contingência, algo que somente pode ser experimentado pelo sujeito como uma espécie de quociente de irracionalidade um tanto perturbador. O capital torna o mercado ao mesmo tempo dinâmico e instável, fazendo com que o Outro do mercado se torne inconsistente, ou seja, sem nenhuma garantia de regulação propriamente dita. Não é, nesse sentido, contra o fetichismo da mercadoria que se levanta o proletariado, ele somente sente-se interpelado pela mais-valia, por aquilo que, para o Outro do mercado, nele mesmo, é mais que ele mesmo, o objeto a.

Nesse caso, convém aqui entendermos bem aquilo que afirmamos anteriormente acerca da relação entre a perda e a recuperação. A espoliação e a produção do excedente não se opõem realmente. $\mathrm{O}$ vocabulário da falta e da perda deve ser entendido como a tradução consciente do próprio núcleo êxtimo e excedentário do sujeito. O objeto a deve, então, ser entendido como o conceito que estenografa uma identidade de propriedades contrárias, ao mesmo tempo como um nada, como um vazio no campo da representação, e, simultaneamente, como alguma coisa, isto é, um elemento discreto e localizável na estrutura: ele erige-se pela sobreposição entre a positividade e a negatividade, pela identidade entre a substância e o atributo e entre o efeito e a causa.

Todos conhecemos a famosa proposição lacaniana segundo a qual é Marx o inventor do sintoma. Lacan (1975) o enuncia em sua lição do 19 de fevereiro de 1975, durante seu vigésimo segundo seminário, intitulado RSI: "Buscar a origem da noção de sintoma, o qual não deve ser buscado em Hipócrates, mas em Marx" (p. 101). É por esse motivo que Lacan afirma que o proletariado é a verdade do capital, pois reduzindo o homem ao estatuto do proletariado, transforma a noção de essência em seu oposto, ou seja, na realização de um conflito. O proletariado deve aqui ser entendido como sintoma, ou seja, como uma forma de tornar presente um conflito fundamental, de um antagonismo de estrutura, como a realização concreta do excesso do gozo pulsional.

Em outras palavras, tal como o sintoma, o proletariado é, ao mesmo tempo, o gozo do capital encarnado e aquilo que, tendendo ao seu próprio excesso, faz com que as coisas não andem mais tão bem assim, exigindo uma redeterminação de sua própria economia, ou seja, um momento revolucionário.
Em outras palavras, o proletariado, ao mesmo tempo em que retira sua identidade de sua condição alienada, encontra a si mesmo determinado como função messiânica, ou seja, projetado no futuro de maneira revolucionária. Ou, como diz Lacan (1975): “de ser depenado de tudo, ele [o proletariado] está encarregado de ser o messias do futuro" (p. 101). É nesse sentido que ele realiza concretamente uma contradição de estrutura no plano da realidade social e encarna, por isso mesmo, o movimento propriamente dialético, pois é tanto a manifestação do conflito quanto a exigência de interpretação. O proletariado é, assim, a verdade do capitalismo da mesma maneira que o sintoma é a verdade do neurótico (no sentido de que o recalcado e seu retorno são a mesma coisa).

\section{Conclusão}

Sabemos o quanto foi sumariamente apresentado o percurso através do qual se pretendeu ilustrar o núcleo central do diálogo de Lacan com Marx: a articulação entre sujeito, Outro e gozo. No entanto, tal percurso serviu para nos inspirar uma crença de ordem doutrinária, segundo a qual, situar corretamente o lugar de Marx no ensino de Lacan pode contribuir de maneira eminente para a compreensão de momentos bastante importantes da orientação lacaniana. Tal passagem pelo diálogo de Lacan com Marx tornaria, sobretudo, compreensível o gesto eminentemente crítico do psicanalista francês no interior da história do movimento psicanalítico, semelhante então àquele do próprio Marx contra a Economia Política Clássica.

Quanto a isso, lembremos que Althusser (1973), em seu Lire Le Capital, assinalava que compreender plenamente o projeto de Marx e, logo, o objeto do capital, implicava ser capaz de situar a diferença específica que separa o tratamento marxiano da economia política daquele realizado dentro do quadro da economia política clássica, na medida em que esta naturalizava uma forma econômica particular como se fosse a forma natural de todo sistema de produção. Nesse sentido, a diferença específica, tanto de Marx com respeito à economia política tradicional quanto a de Lacan com respeito ao pósfreudismo, concerne à lógica estrutural presente em ambas as doutrinas, capazes de cernir um objeto que é, em sua própria definição, contraditório. Podemos dizer que com cada uma de suas respectivas doutrinas, Lacan e Marx, parafraseando Althusser, buscam tornar visíveis nossas formas habituais de autoapreensão, a natureza fabricada do intuitivo e do espontâneo de nossa individualidade concreta, buscando, assim, as condições simbólicas do impensado existente no coração do sujeito da modernidade (p. 16-17).

\section{Referências}

Althusser, L. (1973). Lire le capital. Paris: P.U.F.

Bensussan, G., \& Labica, G. (1985). Dictionnaire critique $d u$ marxisme. Paris: P.U.F.

Blanco, M. (2002) Le trait d'esprit de Freud à Lacan. In Savoirs et clinique. $\mathrm{n}^{\circ} 1$. (pp. 75-96). DOI: 10.3917/sc.001.0075. ISSN: 1634-3298. URL: www.cairn.info/revue-savoirs-et-cliniques2002-1-page-75.htm. Consultado em 13/04/2016. 
Dolar, M. (1998). Cogito as the subject of the unconscious. In S. Zizek (Org.), Cogito And The Unconscious (pp. 11-40). Durham, London: Duke University Press.

Freud, S. (1988). Le mot d'esprit et sa relation à l'inconscient. Paris: Gallimard. (Original publicado em 1905)

Freud, S. (1968). Pulsions et destins des pulsions. In Métapsychologie (pp. 11-43). Paris: Gallimard. (Trabalho original publicado em 1915)

Freud, S. (1984). Nouvelles conférences d'introduction à la psychanalyse. Paris: Gallimard. (Original publicado em 1933)

Jakobson, R. (1963). Essais de linguistique générale. Paris: Éditions de Minuit.

Lacan, J. (1999). O Seminário, Livro $V$-As formações do inconsciente. Rio de Janeiro: Jorge Zahar Editor. (Original publicado em 1957-1958)

Lacan, J. (2008). O Seminário, Livro VII - A Ética da psicanálise. Rio de Janeiro: Jorge Zahar Editor. (Original publicado em 1959-1960)
Lacan, J. (1988). O Seminário, Livro XI - Os quatro conceitos fundamentais da psicanálise. Rio de Janeiro: Jorge Zahar Editor. (Original publicado em 1964)

Lacan, J. (2008). O Seminário, Livro XIV - A lógica do fantasma. Recife: Centro de estudos freudianos do Recife. (Original publicado em 1966-1967)

Lacan, J. (2008). O Seminário, Livro XVI-De um Outro ao outro. Rio de Janeiro: Jorge Zahar Editor. (Original publicado em 1968-1969)

Lacan, J. (1992). O Seminário, Livro XVII-O avesso da psicanálise. Rio de Janeiro: Jorge Zahar Editor. (Original publicado em 1969-1970)

Lacan, J. (1975). RSI. Paris: AFI.

Marx, K. (1993). Le capital. - livre I. Paris: P.U.F. (Original publicado em 1867)

Zizek, S. (1991). O mais sublime dos histéricos. Rio de Janeiro: Jorge Zahar Editor.

Zizek, S. (1992). Eles não sabem o que fazem - O sublime objeto da ideologia. Rio de Janeiro: Jorge Zahar Editor.

Recebido em 10.03.2014

Primeira decisão editorial em 12.03.2015

Versão final em 12.04.2015

Aceito em 17.04.2015 